\title{
The Systematics of South American Quaternary Mammals with Holarctic Origins - an Introduction to the I FOGEMI Proceedings Volume
}

\author{
Leonardo dos Santos Avilla • Dimila Mothé
}

Published online: 13 January 2013

(C) Springer Science+Business Media New York 2013

This special issue of the Journal of Mammalian Evolution represents the proceedings from a meeting held in conjunction with the VII Brazilian Symposium on Vertebrate Paleontology, entitled "First Forum of the Group of Specialists on Immigrant Mammals" (I FOGEMI). This meeting gathered researchers on the systematics of South American Quaternary mammals with holarctic origins. In this brief introduction to the meeting proceedings, we discuss the justification for the meeting, quote its main results, and introduce the contents of the present volume.

The intent of the First Forum of the Group of Specialists on Immigrant Mammals (I FOGEMI, I Fórum do Grupo de Especialistas em Mamiferos Invasores) was to join scientists conducting research on the systematics of South American Quaternary mammals with holarctic origins. Most of these studies were theses and dissertations, mainly conducted by Brazilian paleontologists. Therefore, the I FOGEMI was one of the special events of the VII Simpósio Brasileiro de Paleontologia de Vertebrados (VII SBPV, Seventh Brazilian Symposium on Vertebrate Paleontology), which occurred from the 18th to 23rd July of 2010, at the Universidade Federal do Estado do Rio de Janeiro (UNIRIO), Rio de Janeiro, Brazil.

L. dos Santos Avilla $(\bowtie)$

Departamento de Zoologia, Instituto de Biociências, Laboratório de Mastozoologia, Universidade Federal do Estado do Rio de Janeiro, Avenida Pasteur, 458, Urca, 22290-240, Rio de Janeiro, Brazil

e-mail: leonardo.avilla@gmail.com

\section{Mothé}

Programa de Pós-graduação em Ciências Biológicas (Zoologia), Museu Nacional/UFRJ, Quinta da Boa Vista, 20940-040, Rio de Janeiro, Brazil

e-mail: dimothe@hotmail.com
All researchers invited for the I FOGEMI attended the event (Fig. 1), and we gathered during three days, from the 19th to 21 st of July, 2010. The I FOGEMI was an open event for the participants of the VII SBPV, and it was composed of a series of oral presentations. At the end of the third day, all participants (including the audience) were invited to debate about the main issues highlighted during the event. The oral presentations of the I FOGEMI became the papers in this special volume.

These papers present taxonomic revisions and biogeographical inferences, mostly based on new phylogenetic studies for Gomphotheriidae (Proboscidea), Camelidae, Tayssuidae (Artiodactyla), and Tapiridae (Perissodactyla). Furthermore, another paper demonstrates new ideas about the controversial issue on the ecological displacement and consecutive extinction of the Sparassodonta (Metatheria), a South American native carnivorous group, by the holarctic Carnivora. Moreover, there is a paper on new absolute datings for Brazilian Pleistocene mammals.

The main results of these papers suggest that the ingression of holarctic mammals in South America occurred in several independent pulses on each of the lineages. Also, probably, these ingressions happened from the upper Miocene on, and not only after the imposition of the Panamanian Isthmus. The ingression of holarctic Carnivora is not related to the extinction of the South American native mammalian carnivores, the Sparassodonta. The southern Brazilian Pleistocene mammals were represented by a mixture of "Brazilian" and Pampean Quaternary mammals, and they occurred throughout the Pleistocene. However, some Pampean faunal elements apparently went extinct earlier in Argentina and Uruguay.

Apart from the papers present here, the main conclusions of the I FOGEMI were: 1) some other groups of South American Pleistocene mammals with holarctic origins, such as Cervidae, Equidae, and Sigmodontinae, require taxonomic revisions; in consequence, this would stimulate phylogenetical and 
Fig. 1 Participants of the I FOGEMI: 1) Francisco Prevosti; 2) Leonardo Avilla; 3) Camila Bernardes; 4) Mario Cozzuol; 5) Dimila Mothé; 6) Gérman Gasparini; 7) Carolina Scherer; 8) Renato Lopes; and 9) Elizete Holanda
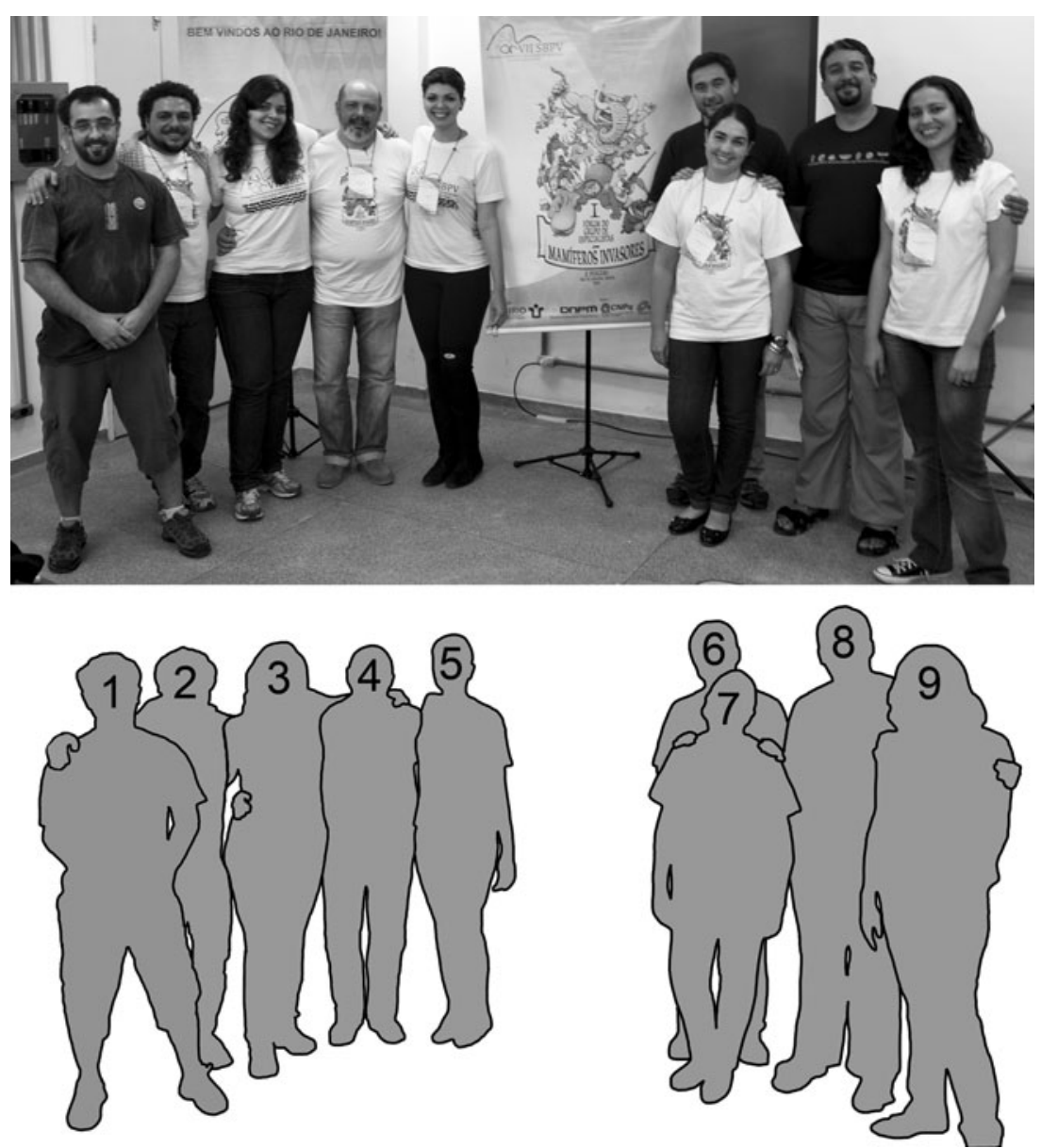

biogeographical research programs for those groups; 2) the Great American Biotic Interchange (GABI), as known, must be revised; and 3) South American Pleistocene mammals, except for the Pampeans, need more absolute dates.

We would like to acknowledge the editor of the Journal of Mammalian Evolution, John R. Wible, for embracing the idea of this proceedings of the I FOGEMI; Camila
Bernardes (UNIRIO) and Carolina Scherer for helping with the I FOGEMI organization; UNIRIO for the logistical assistance for the VII SBPV and I FOGEMI; Fundação de Amparo à Pesquisa do Estado do Rio de Janeiro (FAPERJ) and the Conselho Nacional de Desenvolvimento Científico e Tecnológico (CNPq) for financial support; and all the attendants of the I FOGEMI. 